\title{
Disseminated intravascular coagulation with the fibrinolytic phenotype predicts the outcome of patients with out-of-hospital cardiac arrest
}

Takeshi Wada, Satoshi Gando*, Yuichi Ono, Kunihiko Maekawa, Kenichi Katabami, Mineji Hayakawa and Atsushi Sawamura

\begin{abstract}
Background: We tested the hypothesis that disseminated intravascular coagulation (DIC) during the early phase of post-cardiopulmonary resuscitation (CPR) is associated with systemic inflammatory response syndrome (SIRS), multiple organ dysfunction syndrome (MODS) and affects the outcome of out-of-hospital cardiac arrest (OHCA) patients.

Methods: A review of the computer-based medical records of OHCA patients was retrospectively conducted and included 388 patients who were divided into DIC and non-DIC patients based on the Japanese Association for Acute Medicine DIC diagnostic criteria. DIC patients were subdivided into two groups: those with and without hyperfibrinolysis. Pre-hospital factors, platelet count, coagulation and fibrinolysis markers and lactate levels within $24 \mathrm{~h}$ after resuscitation were evaluated. The outcome measure was all-cause hospital mortality.

Results: DIC patients exhibited lower platelet counts, prolonged prothrombin time, decreased levels of fibrinogen and antithrombin associated with increased fibrinolysis than those without DIC. DIC patients more frequently developed SIRS and MODS, followed by worse outcomes than non-DIC patients. The same changes were observed in DIC patients with hyperfibrinolysis who showed a higher prevalence of MODS, leading to worse outcome than those without hyperfibrinolysis. Logistic regression analyses showed that lactate levels predicted hyperfibrinolysis and DIC is an independent predictor of patient death. Survival probabilities of DIC patients during hospital stay were significantly lower than non-DIC patients. The area under the receiver operating characteristic curve of DIC for the prediction of death was 0.704 .
\end{abstract}

Conclusions: The fibrinolytic phenotype of DIC during the early phase of post-CPR more frequently results in SIRS and MODS, especially in patients with hyperfibrinolysis, and affects the outcome of OHCA patients.

Keywords: Cardiac arrest, Disseminated intravascular coagulation (DIC), Fibrinolysis, Outcome, Out-of-hospital

\footnotetext{
* Correspondence: gando@med.hokudai.ac.jp

Division of Acute and Critical Care Medicine, Department of Anesthesiology and Critical Care Medicine, Hokkaido University Graduate School of Medicine, N15W7, Kita-ku, Sapporo 060-8638, Japan
}

(c) 2016 The Author(s). Open Access This article is distributed under the terms of the Creative Commons Attribution 4.0 International License (http://creativecommons.org/licenses/by/4.0/), which permits unrestricted use, distribution, and reproduction in any medium, provided you give appropriate credit to the original author(s) and the source, provide a link to the Creative Commons license, and indicate if changes were made. The Creative Commons Public Domain Dedication waiver (http://creativecommons.org/publicdomain/zero/1.0/) applies to the data made available in this article, unless otherwise stated. 


\section{Background}

Whole body ischemia reperfusion due to cardiac arrest constitutes post-resuscitation syndrome resulting from microvascular obstruction-induced tissue hypoxia in many vital organs, which affects the patient's outcome [1]. Microvascular obstruction, referred to as the no reflow phenomenon, in the brain has been attributed to intravascular thrombosis during cardiac arrest $[1,2]$. Post-resuscitation syndrome is now referred to as postcardiac arrest syndrome consisting of four syndromes including systemic ischemia reperfusion responses and post-cardiac arrest brain injury [3]. Main pathophysiologies of the former responses are systemic inflammatory response syndrome (SIRS) and increased coagulation, which clinically manifest as tissue hypoxia/ischemia and multiple organ dysfunctions [3]. Adrie et al. [4] confirmed that successfully resuscitated cardiac arrest was followed by SIRS and activation of coagulation, both of which contributed to organ dysfunction, including the brain. Recent studies have indicated that disseminated intravascular coagulation (DIC) leads to organ dysfunction and affects the prognosis of out-of-hospital cardiac arrest (OHCA) patients $[5,6]$.

Inflammatory cytokine-initiated activation of tissuefactor-dependent coagulation, insufficient control of the anticoagulation pathways, and plasminogen activator inhibitor-1 (PAI-1)-mediated suppression of fibrinolysis characterize the pathogenesis of DIC [7]. From the first report of DIC following cardiac arrest [8], higher levels of tumor necrosis factor- $\alpha$ (TNF- $\alpha$ ), interleukin-6 (IL-6) and IL-8 [4, 9, 10]; increased tissue factor levels [11]; insufficient levels of tissue factor pathway inhibitor (TFPI), antithrombin, protein $\mathrm{C}$ and protein $\mathrm{S}[4,11]$; and increased PAI-1 levels $[12,13]$ have been repeatedly confirmed during cardiopulmonary resuscitation (CPR) and after return of spontaneous circulation (ROSC). These changes lead to massive thrombin generation and consecutive fibrin formation $[4,6,12]$. Importantly, underlying conditions of DIC occasionally cause a simultaneous increase in fibrinolysis resulting from tissue-type plasminogen activator (t-PA), which is referred to as DIC with the fibrinolytic phenotype, as opposed to the thrombotic phenotype associated with elevated PAI-1 levels [14]. Both types of DIC have been recognized to affect the patient's outcome [7, 14].

Marked increases in t-PA antigen and activity levels were followed by the PAI-1 expression during CPR and immediately after ROSC within $24 \mathrm{~h}$ [12]. In this study, therefore, significant imbalances between the levels of t-PA and PAI-1 during the first $24 \mathrm{~h}$ after cardiac arrest and resuscitation was noted which was coincided with the definition of DIC with the fibrinolytic phenotype.

According to the results of these previous studies on DIC, we investigated changes in coagulation and fibrinolysis markers during the first $24 \mathrm{~h}$ after $\mathrm{OHCA}$ and resuscitation. We tested the hypothesis that DIC with the fibrinolytic phenotype during the early phase of post-CPR is associated with SIRS, organ dysfunctions and affects the patient's outcome.

\section{Methods \\ Patient selection and data collection}

From June 2000 to December 2011, all consecutive patients older than 12 years of age with successful ROSC from OHCA who were admitted to the ICU were eligible for this study. Patients who suffered to cardiac arrest due to trauma or burns, those on warfarin therapy, those with end-stage liver diseases, terminal illnesses or profound hypothermia, and those underwent percutaneous cardiopulmonary support (PCPS) were excluded. The Institutional Review Board of our institution approved this study and issued a waiver of informed consent.

A systematic review of the computer-based medical records of these patients was retrospectively conducted to provide baseline characteristics and DIC-related variables. Data regarding the platelet count, prothrombin time, prothrombin time ratio, fibrinogen, antithrombin, fibrin/fibrinogen degradation products (FDP), D-dimer and lactate were obtained at 4 time points within $24 \mathrm{~h}$ after successful ROSC: Time Point 01, immediately after ROSC to $4 \mathrm{~h}$ after ROSC; Time Point 02,4 to $8 \mathrm{~h}$ after ROSC; Time Point 03, 8 to $16 \mathrm{~h}$ after ROSC; and Time Point 04, 16 to $24 \mathrm{~h}$ after ROSC. Day 0 data indicates the highest or lowest values of these 4 points measurements. Namely, the maximal worst values during this time period were considered for classfiyng patients with or without DIC and for determining the phenotype. The standard practice in our ICU for all patients is to draw blood several times a day in order to analyze the laboratory data including platelet count, coagulation and fibrinolysis. Blood gas analyses with lactate measurements were also frequently performed.

\section{Study setting and definitions}

The levels of care provided by the emergency medical technicians (EMT) in our country are comparable to other advanced countries worldwide. The management of cardiac arrest was based on the 2000, 2005, and 2010 guidelines proposed by the International Liaison Committee on Resuscitation. Detailed pre-hospital care and CPR methods in our department can be found elsewhere [15].

Successful ROSC was defined as measurable blood pressure and pulse for more than $1 \mathrm{~h}$ and admission to the ICU, regardless of catecholamine use. Organ dysfunction was assessed by the Sequential Organ Failure Assessment (SOFA) score [16]. Multiple organ dysfunction syndrome (MODS) was defined as a SOFA score $\geq 12$ [16]. The SIRS score was calculated according to the 
American College of Chest Physicians/Society of Critical Care Medicine consensus conference [17]. The diagnosis of DIC was made based on the Japanese Association for Acute Medicine (JAAM) DIC diagnosis criteria using day 0 data [18]. When the total score was $\geq 4$, the DIC was established. The DIC phenotype was defined with reference to the criteria of Asakura, hyperfibrinolysis was defined as an FDP level of $\geq 100 \mu \mathrm{g} / \mathrm{mL}$, and the FDP/D-dimer ratio was used as a surrogate marker of fibrin (ogen) olysis [14]. Tissue hypoperfusion was defined as a blood lactate level of $\geq 4 \mathrm{mmol} / \mathrm{L}$ based on the Surviving Sepsis Campaign Guidelines 2012 [19]. The outcome measure was the hospital all-cause mortality.

\section{Statistical analysis}

Data are presented as the median and interquartile range. The IBM SPSS 22.0 for MAC OSX software program (IBM Japan, Tokyo) was used for the statistical analyses and calculations. Comparisons between the two groups were performed with the Mann-Whitney $U$ test and either the Chi-square test or Fisher's exact test when required. The relationships between the dependent and the independent variables were analyzed by a logistic regression analysis (the backward stepwise method based on likelihood) and the results were reported as the odds ratio and
$95 \%$ confidence intervals. The discriminatory performance for hospital death was evaluated using the area under the receiver operating characteristic (ROC) curve (AUC). Survival curves during hospital stay were derived according to the Kaplan-Meier methods and compared using the $\log$-rank test. Differences with $p$-values $<0.05$ were considered to be statistically significant.

\section{Results}

\section{Baseline patient characteristics}

During the study period, a total of 1243 OHCA patients presented to our Emergency Department. After the exclusion of ineligible patients and patients with incomplete data for calculation of the DIC score, those performed PCPS were further excluded. Finally, 388 eligible patients were identified, who were divided into DIC $(n=208)$ and non-DIC patients $(n=180)$.

Table 1 shows the demographic data of the patients. Cardiac arrest due to a cardiac origin was less frequent in DIC patients. All DIC patients developed SIRS. DIC patients exhibited higher SIRS and SOFA scores associated with MODS, which associated with a significantly higher mortality than non-DIC patients (54.8\% vs. $23.9 \%$ ). Although some data were lacking (DIC, $n=182$; Non DIC, $n=163$ ), the Acute Physiology and Chronic

Table 1 Demographic and clinical characteristics of all patients

\begin{tabular}{|c|c|c|c|}
\hline & $\begin{array}{l}\text { Non DIC } \\
(180)\end{array}$ & $\begin{array}{l}\text { DIC } \\
(208)\end{array}$ & $p$ Value \\
\hline Age (year) & $66(55-76)$ & $71(58-80)$ & 0.020 \\
\hline Male sex $(n, \%)$ & $112(62.2)$ & $124(59.6)$ & 0.604 \\
\hline \multicolumn{4}{|l|}{ Causes of cardiac arrest } \\
\hline CNS/Cardiac/Respiratory/Asphyxia/Other/Unknown & $13 / 99 / 24 / 32 / 11 / 1$ & $18 / 86 / 30 / 37 / 32 / 5$ & - \\
\hline Cardiac $(n, \%)$ & $99(55.0)$ & $86(41.3)$ & 0.008 \\
\hline \multicolumn{4}{|l|}{ Initial rhythm } \\
\hline VF/Asystole/PEA/Pulseless VT/Unknown & $32 / 41 / 33 / 3 / 71$ & $24 / 75 / 35 / 6 / 24$ & - \\
\hline Shockable rhythm $(n, \%)$ & $35(19.4)$ & $30(14.4)$ & 0.220 \\
\hline Witnessed arrest & $75(41.7)$ & $92(44.2)$ & 0.681 \\
\hline Bystander CPR $(n, \%)$ & $55(30.6)$ & $50(24.0)$ & 0.169 \\
\hline Shock by EMT $(n, \%)$ & $42(23.3)$ & $44(21.1)$ & 0.626 \\
\hline Therapeutic hypothermia $(n, \%)$ & $44(24.4)$ & $40(19.2)$ & 0.219 \\
\hline DIC score & $2(1-2)$ & $5(4-6)$ & 0.000 \\
\hline SIRS score & $3(3-4)$ & $4(3-4)$ & 0.048 \\
\hline $\operatorname{SIRS}(n, \%)$ & $178(98.9)$ & $208(100)$ & 0.215 \\
\hline SOFA day 0 score & $6(4-8)$ & $9(6-11)$ & 0.000 \\
\hline MODS day $0(n, \%)$ & $7(3.9)$ & 49 (23.6) & 0.000 \\
\hline MODS day $5(n, \%)$ & $10(5.5)$ & $67(32.2)$ & 0.000 \\
\hline Outcome death $(n, \%)$ & $43(23.9)$ & $114(54.8)$ & 0.000 \\
\hline
\end{tabular}

CNS central nervous system, VF ventricular fibrillation, $P E A$ pulseless electrical activity, $V T$ ventricular tachycardia, CPR cardiopulmonary resuscitation, EMT emergency medical technician, DIC disseminated intravascular coagulation, APACHEII Acute Physiology and Chronic Health Evaluation II, SIRS systemic inflammatory response syndrome, SOFA sequential organ failure assessment, MODS multiple organ dysfunction syndrome 
Health Evaluation II scores of the DIC patients [34 (29-38)] were significantly higher than those of the nonDIC patients [29 $(24-33)](P<0.001)$, suggesting that conditions of the DIC patients were more severe.

\section{Serial changes in measured variables}

DIC patients continuously showed lower platelet counts, more prolonged prothrombin time ratios, and lower levels of fibrinogen and antithrombin than non-DIC patients (Fig. 1). Extremely high levels of FDP and D-dimer associated with marked increases in lactate levels were also observed in DIC patients (Fig. 2). In addition, FDP/ D-dimer ratios in DIC patients were significantly higher than in non-DIC patients (Fig. 3). These results suggest consumption coagulopathy, insufficient anticoagulation, fibrin (ogen) olysis, and tissue hypoperfusion in DIC patients and that the DIC belongs to the fibrinolytic phenotype. The numbers of patients at each time point are provided in Additional file 1: Table S1.

\section{Subgroup analyses of DIC patients}

DIC patients were subdivided into those with $(n=73)$ and without $(n=135)$ hyperfibrinolysis (Table 2$)$. The markers of fibrinolysis and lactate levels of DIC patients with hyperfibrinolysis are presented in Table 3. Patients with hyperfibrinolysis had higher DIC and SOFA scores. Furthermore, MODS in these patients continued from day 0 to day 5 , leading to a higher mortality rate of $68.5 \%$ in comparison to patients without hyperfibrinolysis $(41.7 \%)$. The median FDP/D-dimer ratio of 2.0 in patients with hyperfibrinolysis was significantly higher than that in those without hyperfibrinolysis (Table 3). In addition, the lactate levels were significantly higher in those with hyperfibrinolysis than in those without fibrinolysis. These results suggest that DIC with hyperfibrinolysis is considered to be more severe DIC associated with extreme fibrin (ogen) olysis and tissue hypoperfusion, which results in worse outcome.

\section{Outcome analyses}

Stepwise logistic regression analyses confirmed that DIC, SOFA scores, and lactate levels are independent predictors of patient death (Table 4). Hyperfibrinolysis also predicted patient death (Table 5). Table 5 shows that tissue hypoperfusion (as indicated by lactate level) is one of the causes of hyperfibrinolysis. ROC curves showed a significant discriminative performance of DIC and SOFA scores and lactate levels for patient death (Fig. 4). These
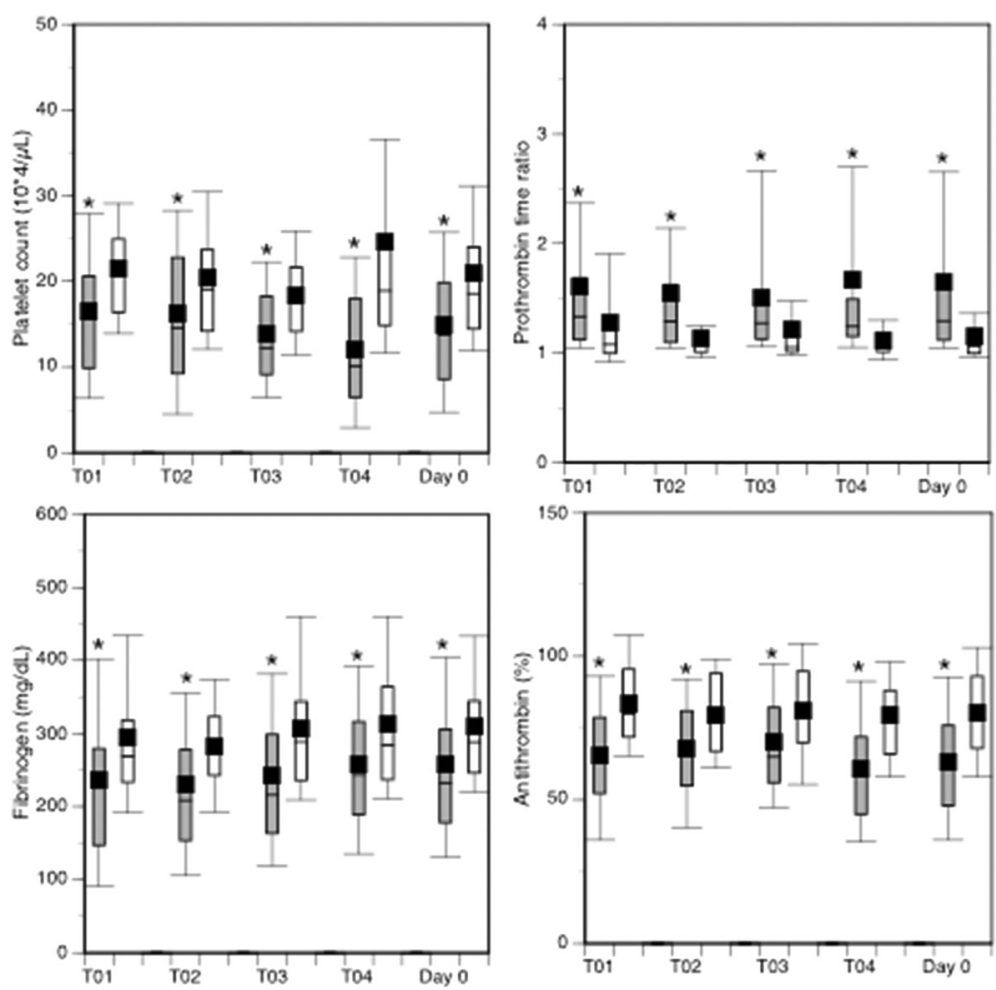

Fig. 1 Box plots showing serial changes in the platelet counts, prothrombin time ratios, fibrinogen and antithrombin levels during the first $24 \mathrm{~h}$ in successfully resuscitated patients after OHCA. DIC patients (grey boxes) showed significantly lower platelet counts, more prolonged prothrombin time ratios, lower levels of fibrinogen and antithrombin than non-DIC patients (open boxes). Horizontal bars in the box indicate the median (middle) and interquartile ranges (upper $25 \%$, lower $75 \%$ ). Black squares in the box indicate the mean value. Top and bottom bars indicate the maximum and minimum values, respectively. ${ }^{*} p<0.001$ vs. non-DIC patients 


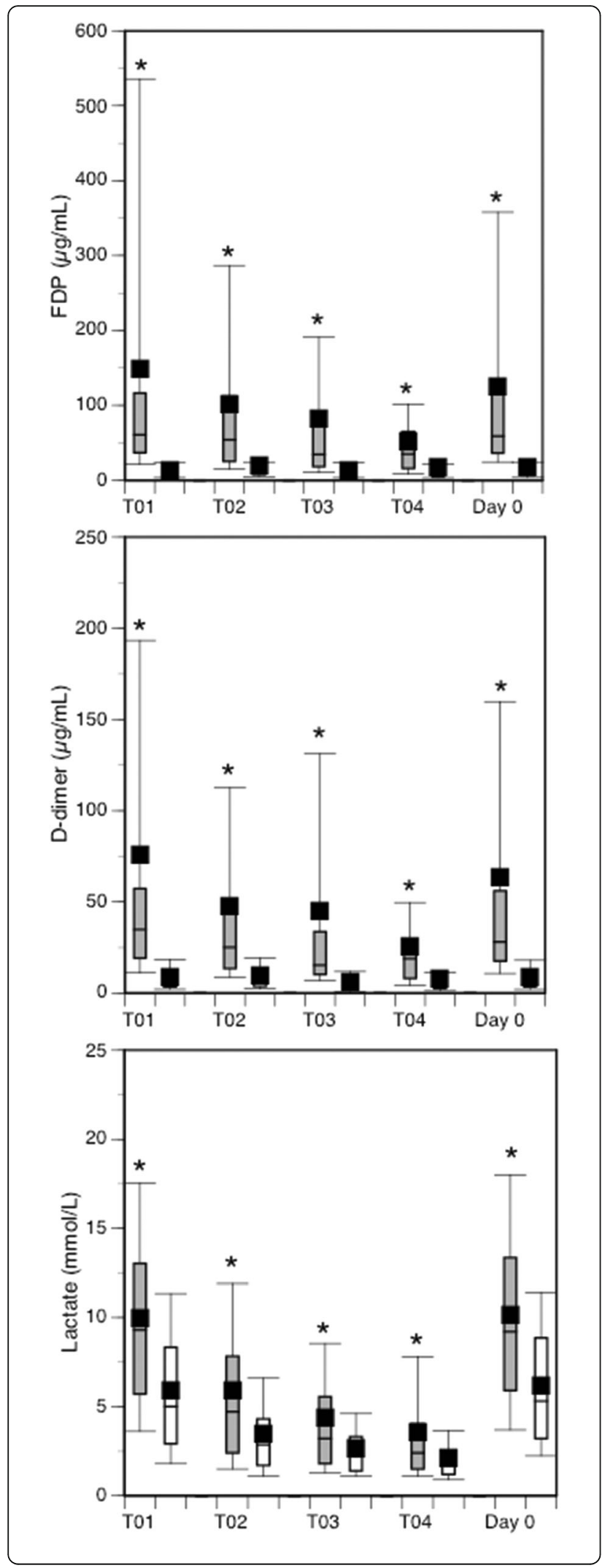

Fig. 2 Box plots showing serial changes in FDP, D-dimer and lactate levels. DIC patients (grey boxes) showed significantly higher values of three variables than non-DIC patients (open boxes). Horizontal bars in the box indicate the median (middle) and interquartile ranges (upper $25 \%$, lower $75 \%$ ). Black squares in the box indicate the mean value. Top and bottom bars indicate the maximum and minimum values, respectively. ${ }^{*} p<0.001$ vs. non-DIC patients

results are important because the DIC score (score of one organ dysfunction [blood]) showed good discriminative power for the outcome compared with the SOFA score (score of multiple organ dysfunction). Kaplan-Meier curves showed that DIC, especially DIC with hyperfibrinolysis, significantly affected patient death (Fig. 5).

\section{Discussion}

The results of the present study demonstrate that OHCA patients with DIC during the early phase of post CPR are at risk of SIRS and MODS and that their condition is associated with a poor prognosis. The markedly higher FDP and D-dimer levels, and FDP/D-dimer ratio indicate that this type of DIC belongs to DIC with the fibrinolytic phenotype accompanied by fibrin (ogen) olysis. The outcomes of DIC patients with hyperfibrinolysis were worse than those observed in DIC patients without hyperfibrinolysis. The results of the logistic regression analyses suggest

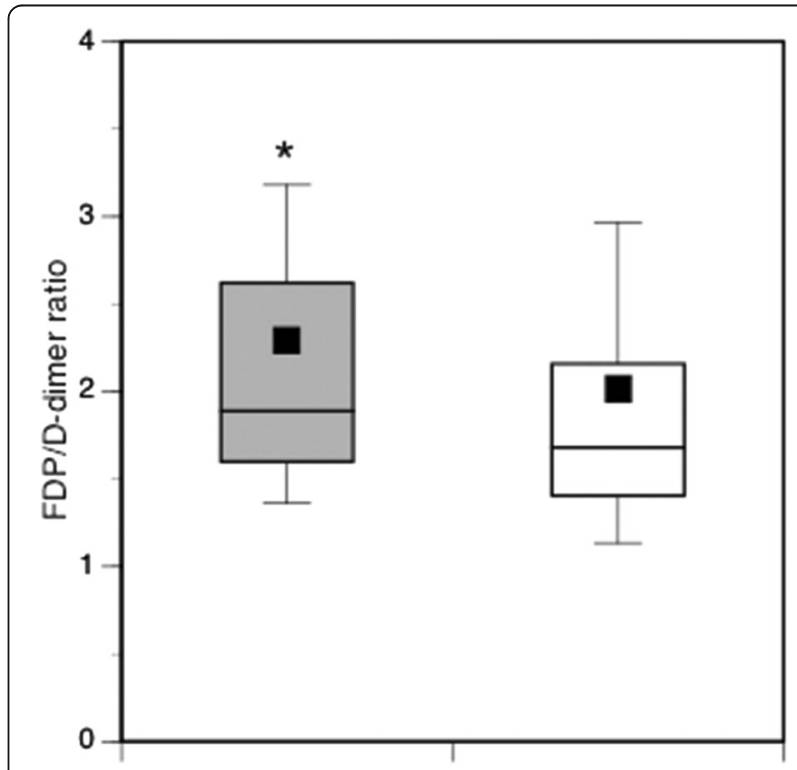

Fig. 3 Box plots showing FDP/D-dimer ratios between DIC (grey boxes) and non-DIC patients (open boxes). DIC patients exhibited significantly higher ratios than non-DIC patients. Horizontal bars in the box indicate the median (middle) and interquartile ranges (upper $25 \%$, lower $75 \%$ ). Black squares in the box indicate the mean value. Top and bottom bars indicate the maximum and minimum values, respectively. ${ }^{*} p<0.001$ vs. non-DIC patients 
Table 2 Demographic and clinical characteristics of the DIC patients

\begin{tabular}{|c|c|c|c|}
\hline & \multicolumn{2}{|l|}{$\mathrm{DIC}$} & \multirow[b]{2}{*}{$p$ Value } \\
\hline & $\begin{array}{l}\text { Hyperfibrinolysis No } \\
\text { (135) }\end{array}$ & $\begin{array}{l}\text { Hyperfibrinolysis Yes } \\
\text { (73) }\end{array}$ & \\
\hline Age (year) & $70(58-79)$ & $73(59-82)$ & 0.091 \\
\hline Male sex $(n, \%)$ & $78(57.8)$ & $46(63.0)$ & 0.554 \\
\hline \multicolumn{4}{|l|}{ Causes of cardiac arrest } \\
\hline Cardiac $(n, \%)$ & $54(40.0)$ & $32(43.8)$ & 0.659 \\
\hline \multicolumn{4}{|l|}{ Initial rhythm } \\
\hline Shockable rhythm $(n, \%)$ & $22(16.3)$ & $8(11.0)$ & 0.408 \\
\hline Witnessed arrest & $59(43.7)$ & $33(45.2)$ & 0.884 \\
\hline Bystander CPR $(n, \%)$ & $28(20.7)$ & $22(30.1)$ & 0.173 \\
\hline Shock by EMT (n,\%) & $27(20.0)$ & $17(23.3)$ & 0.597 \\
\hline Therapeutic hypothermia $(n, \%)$ & $30(22.2)$ & $10(13.7)$ & 0.146 \\
\hline DIC score & $5(4-5)$ & $5(4.5-6)$ & 0.000 \\
\hline SIRS score & $3(3-4)$ & $4(3-4)$ & 0.359 \\
\hline $\operatorname{SIRS}(n, \%)$ & $135(100)$ & $73(100)$ & - \\
\hline SOFA day 0 score & $8(6-11)$ & $10(7-13)$ & 0.001 \\
\hline MODS day $0(n, \%)$ & $23(17.0)$ & $26(35.6)$ & 0.004 \\
\hline MODS day $5(n, \%)$ & $36(26.7)$ & $31(42.5)$ & 0.029 \\
\hline Outcome death $(n, \%)$ & $64(47.4)$ & $50(68.5)$ & 0.004 \\
\hline
\end{tabular}

CNS central nervous system, $V F$ ventricular fibrillation, $P E A$ pulseless electrical activity, $V T$ ventricular tachycardia, $C P R$ cardiopulmonary resuscitation, $E M T$ emergency medical technician, DIC disseminated intravascular coagulation, SIRS systemic inflammatory response syndrome, SOFA sequential organ failure assessment, MODS multiple organ dysfunction syndrome

that tissue hypoperfusion, as evaluated by the lactate level, may be a cause of increased fibrinolysis.

Kim et al. [5] found that an increased initial DIC score in OHCA patients was an independent predictor for poor outcomes and early mortality risk. OHCA patients with a higher $\mathrm{D}$-dimer level on admission had a poor outcome and the D-dimer levels were independent predictor of mortality [20]. Although hyperfibrinolysis was assessed by maximum lysis of rotational thromboelastometry, OHCA patients associated with hyperfibrinolysis showed a higher mortality rate, and hyperfibrinolysis was correlated with markers of tissue hypoperfusion including $\mathrm{pH}$, base excess and lactate levels [21, 22]. Cardiac arrest due to asphyxia by drowning developed DIC with the fibrinolytic phenotype was associated with lower platelet counts and fibrinogen levels, prolonged

Table 3 Markers of fibrinolysis and lactate levels between DIC patients with and without hyperfibrinolysis

\begin{tabular}{llll}
\hline & $\begin{array}{l}\text { Hyperfibrinolysis No } \\
(135)\end{array}$ & $\begin{array}{l}\text { Hyperfibrinolysis Yes } \\
(73)\end{array}$ & $p$ Value \\
\hline FDP $(\mu \mathrm{g} / \mathrm{mL})$ & $42.5(28.2-57.6)$ & $186.0(110.3-404.5)$ & 0.000 \\
D-dimer $(\mu \mathrm{g} / \mathrm{mL})$ & $20.3(14.4-28.2)$ & $74.3(49.9-182.5)$ & 0.000 \\
FDP/D-dimer & $1.8(1.5-2.5)$ & $2.0(1.7-2.9)$ & 0.007 \\
Lactate $(\mathrm{mmol} / \mathrm{L})$ & $8.1(5.3-11.1)$ & $11.3(8.5-15.6)$ & 0.000 \\
\hline
\end{tabular}

Day 0 data are used for the FDP, D-dimer, and FDP/D-dimer values. The lactate data was obtained using data from time point 01 prothrombin time, and significantly higher D-dimer levels, which led to a worse outcome [23]. The present study has importance in that it validates the previous studies, which separately confirmed the importance of DIC or increased fibrinolysis, and provides a unified concept of DIC with the fibrinolytic phenotype. It also reveals that this DIC phenotype is associated with an increased risk of mortality, especially those with hyperfibrinolysis.

For a long time, anoxia and endothelial injury were believed to be clearly established triggering stimuli for the appearance of circulating fibrinolytic activator and

Table 4 Stepwise logistic regression analyses for prediction of the outcome (death)

\begin{tabular}{lccl}
\hline & Odds ratio & $p$ Value & 95 \% confidence interval \\
\hline DIC score & 1.171 & 0.041 & $1.006-1.364$ \\
SOFA score & 1.178 & 0.001 & $1.073-1.292$ \\
Lactate & 1.129 & 0.000 & $1.065-1.0197$ \\
Witnessed arrest & 0.637 & 0.081 & $0.385-1.057$ \\
Cardiac origin & 0.449 & 0.003 & $0.266-0.756$ \\
Shockable rhythm & 0.400 & 0.024 & $0.180-0.887$
\end{tabular}

The results of the final step of the analyses are shown. The dependent variables on the first steps: age, sex, DIC score (day 0), SOFA score (day 0), SIRS score (day 0), lactate level (time point 01 ), witnessed arrest, bystander CPR, shock by EMT, cardiac origin, and shockable rhythm

DIC disseminated intravascular coagulation, SOFA sequential organ failure assessment, SIRS systemic inflammatory response syndrome, $C P R$ cardiopulmonary resuscitation, EMT emergency medical technician 
Table $\mathbf{5}$ Logistic regression analyses for prediction of the outcome (death) and hyperfibrinolysis in DIC patients

\begin{tabular}{lccc}
\hline & Odds ratio & $p$ Value & $\begin{array}{l}95 \% \text { confidence } \\
\text { interval }\end{array}$ \\
\hline $\begin{array}{l}\text { Outcome (enter method) } \\
\quad \text { SOFA score }\end{array}$ & 1.204 & 0.000 & $1.094-1.324$ \\
$\quad \begin{array}{l}\text { Hyperfibrinolysis } \\
\text { Hyperfibrinolysis (stepwise method) }\end{array}$ & 1.938 & 0.038 & $1.036-3.626$ \\
$\quad$ Age & 1.002 & 0.030 & $1.002-1.043$ \\
$\quad$ Bystander CPR & 0.536 & 0.083 & $0.265-1.085$ \\
Lactate on time point 01 & 1.129 & 0.000 & $1.062-1.196$ \\
\hline
\end{tabular}

The stepwise method shows the results of the final step of the analyses. The dependent variables on the first steps: age, sex, lactate level, witnessed arrest, bystander CPR, shock by EMT, cardiac origin, and shockable rhythm $D I C$ disseminated intravascular coagulation, SOFA sequential organ failure assessment, CPR cardiopulmonary resuscitation, EMT emergency medical technician

increased fibrinolysis [24-26]. Schneiderman et al. [27, 28] confirmed immediate increases in t-PA activity following arterial occlusion-induced ischemia both in humans and a rat model, which is attributable to the release of preexisting t-PA in Weibel-Palade bodies [29]. PAI-1 mRNA is initially expressed $4 \mathrm{~h}$ after hypoxia, followed by the appearance of PAI- 1 antigen at $6 \mathrm{~h}$, and reaches its peak levels at 20 to $24 \mathrm{~h}$ after hypoxia [30]. These chronological changes in the levels of t-PA and PAI-1 completely coincide with the changes in these variables during CPR and after ROSC in patients with OHCA [12]. These results suggest that hypoxia during pre-cardiac

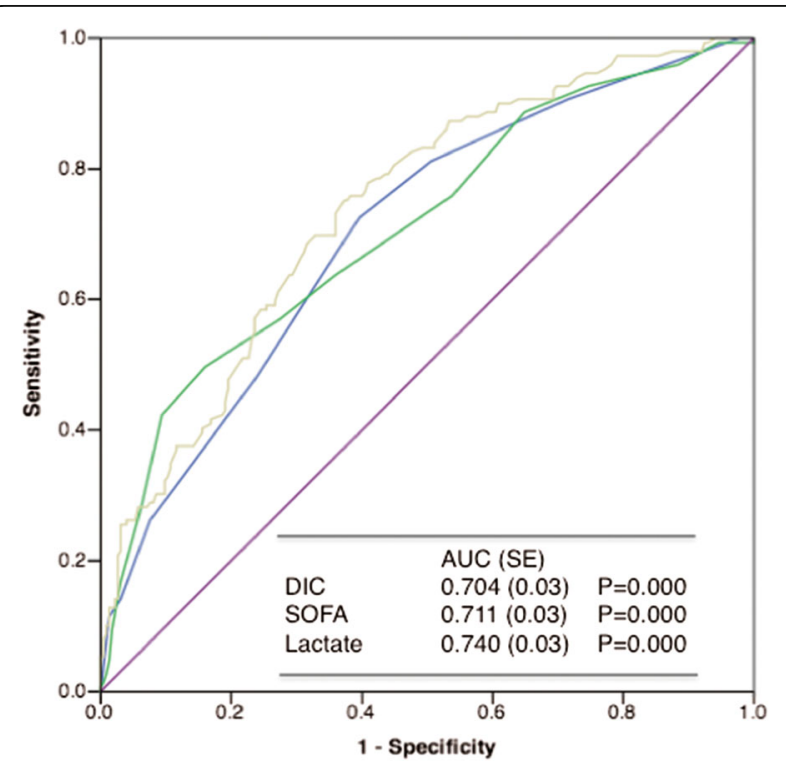

Fig. 4 ROC curves of the DIC scores (blue line), SOFA scores (green line) and lactate levels (yellow line) for the prediction of hospital death of OHCA patients. All of these variables showed a good discriminative power to predict poor outcome of the patients. SE, standard error
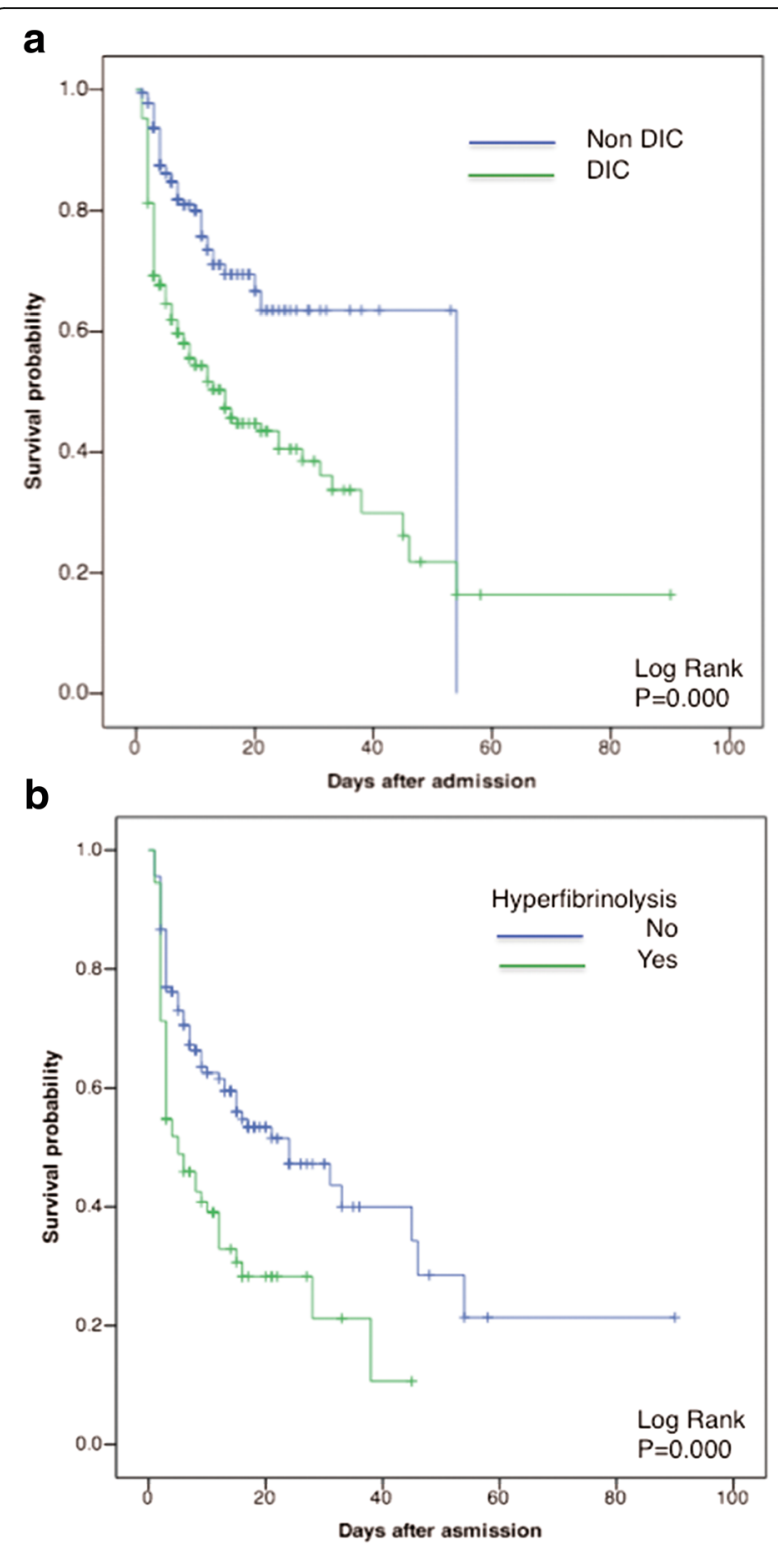

Fig. 5 Kaplan-Meier curves showing the association between DIC (a) or hyperfibrinolysis (b) with hospital mortality. DIC and DIC with hyperfibrinolysis showed a significantly lower survival probability in the hospital than non-DIC patients and DIC without hyperfibrinolysis

arrest, and ischemia/hypoxia during cardiac arrest and CPR result in whole body tissue hypoperfusion recognized as increased lactate levels, which is followed by increased fibrinolysis in DIC patients, as observed in the present and our previous study and asphyxia-induced OHCA patients $[12,23]$.

There are pre-cardiac arrest differences in the perfusion pressure and blood flow and the duration and degree of tissue hypoperfusion, which is dependent on the cause of cardiac arrests, such as shock, exsanguination, asphyxia, and ventricular fibrillation [1]. Ventricular fibrillation indicates sudden onset of ischemia without pre-cardiac arrest 
hypoxia. Therefore, in the present study, a low incidence of cardiac arrest due to a presumed cardiac origin in DIC patients might, in part, explain the finding that causes of cardiac arrest influence the degree of fibrinolysis. However, a subgroup analysis of a previous study confirmed that the magnitude of increased risk of a DIC-dependent poor prognosis in cardiac etiology was similar to that of the overall study population [5]. Many studies have reported that the time to first basic life support and duration of CPR were two of the main causes of hyperfibrinolysis [5, 21-23]. Although these parameters were not obtained in the present study, low odds ratio of bystander CPR in Table 5 indirectly suggests that a shortened ischemia period due to bystander CPR may reduce the risk of hyperfibrinolysis. Lastly, evenly distributed therapeutic hypothermia excluded the effects of hypothermia on DIC and increased fibrinolysis in the present study. Taken together, these results suggest that the duration of hypoxia/ ischemia, but not etiologies of cardiac arrest, may be a primary determinant of the development of DIC with the fibrinolytic phenotype in OHCA patients.

Activated protein $\mathrm{C}$ did not increase in OHCA patients [22]. Another study confirmed that activated protein $\mathrm{C}$ levels are not high enough to inhibit PAI-1 [23]. Neither syndecan-1 nor endothelial heparin sulfate levels were elevated in DIC with the fibrinolytic phenotype observed in asphyxia-induced OHCA [23]. Furthermore, other heparinase-sensitive glycosaminoglycans were not elevated [23]. These results suggest that participations of activated protein $\mathrm{C}$ and phenomena referred to as auto-heparinization are highly unlikely during hyperfibrinolysis in patients with OHCA.

Limitations. The results of the present study is based on retrospective analyses of OHCA in a single center and limited by an incomplete data set. Although increased fibrinolysis can be confirmed, the supposed causes of this phenomenon, such as t-PA and PAI-1, were not measured. Bleeding or a bleeding tendency, and the time to ROSC, and outcome scores such as cerebral performance category were not evaluated due to a lack of data. However, the magnitude of the results of this study suggests that a prospective multicenter study is needed to evaluate the effect of DIC on the outcome of OHCA patients.

\section{Conclusions}

In OHCA patients, DIC during the early phase of postCPR exhibited lower platelet counts, consumption coagulopathy, and insufficient antithrombin levels associated with increased fibrin (ogen) olysis assessed by higher FDP/ D-dimer ratios, which can explain DIC of the fibrinolytic phenotype. DIC patients, especially those with hyperfibrinolysis, more gives rise to MODS associated with SIRS, leading to worse outcomes than those without DIC. Tissue hypoperfusion due to hypoxia and ischemia during cardiac arrest and CPR may be considered to be one of the causes of increased fibrinolysis in this type of DIC. The present study has validated previous studies that separately confirmed existence of DIC or increased fibrinolysis during the early post-CPR phase in OHCA patients. This study has further importance in that it unifies DIC and increased fibrinolysis as a single condition in the fibrinolytic phenotype of DIC and it recognized that this phenotype is associated with poor outcome.

\section{Additional file}

Additional file 1: Table S1. Numbers of the patients. (DOCX $48 \mathrm{~kb}$ )

\begin{abstract}
Abbreviations
CNS: Central nervous system; CPR: Cardiopulmonary resuscitation; DIC: Disseminated intravascular coagulation; EMT: Emergency medical technician; FDP: Fibrin/fibrinogen degradation products; MODS: Multiple organ dysfunction syndrome; OHCA: Out-of-hospital cardiac arrest; PCPS: Percutaneous cardiopulmonary support; PEA: Pulseless electrical activity; ROSC: Return of spontaneous circulation; SIRS: Systemic inflammatory response syndrome; SOFA: Sequential organ failure assessment; VF: Ventricular fibrillation; VT: Ventricular tachycardia
\end{abstract}

\section{Acknowledgements}

None.

Funding

Departmental funding was used for this study.

\section{Availability of data and materials}

The datasets supporting the conclusions of this article are available in the [FigShare] repository [unique persistent identifier and hyperlink to dataset(s) in https://figshare.com/articles/Data_set1_xlsx/3122110].

\section{Authors' contributions}

TW designed the study, interpreted the data, and drafted the manuscript. SG conceived the study, analyzed and interpreted the data, and drafted the manuscript. YO, KM, KK, MH, and AS participated in the study design, helped to draft the manuscript, and proofread the manuscript. All authors read and approved the final manuscript.

\section{Competing interests}

Gando S received payment for lectures from Asahi Kasei Pharma. The other authors declare that they have no conflict of interests.

Consent for publication

Not applicable.

\section{Ethics approval and consent to participate}

The Institutional Review Board of our institution (Hokkaido University Hospital Clinical Research and Medical Innovation (enter) approved this study (No. 012-0035) and issued a waiver of informed consent.

Received: 28 July 2016 Accepted: 30 August 2016

Published online: 21 September 2016

References

1. Safer P, Bircher NG. Prolonged life support. Cardiopulmonary cerebral resuscitation. Basic and advanced cardiac and trauma life support. In: Safer $P$, Bircher NG, editors. An introduction to resuscitation medicine. 3rd ed. Philadelphia: Saunders Company; 1988. p. 229-78.

2. Fisher M, Hossmann KA. No-reflow after cardiac arrest. Intensive Care Med. 1995:21:132-41.

3. Neumar RW, Nolan JP, Adrie C, Aibiki M, Berg RA, Böttiger BW, et al. Postcardiac arrest syndrome: epidemiology, pathophysiology, treatment, and prognostication. A consensus statement from the International Liaison 
Committee on Resuscitation (American Heart Association, Australian and New Zealand Council on Resuscitation, European Resuscitation Council, Heart and Stroke Foundation of Canada, InterAmerican Heart Foundation, Resuscitation Council of Asia, and the Resuscitation Council of Southern Africa); the American Heart Association Emergency Cardiovascular Care Committee; the Council on Cardiovascular Surgery and Anesthesia; the Council on Cardiopulmonary, Perioperative, and Critical Care; the Council on Clinical Cardiology; and the Stroke Council. Circulation. 2008;118:2452-83.

4. Adrie C, Monchi M, Laurrent I, Um S, Yan SB, Thuong M, et al. Coagulopathy after successful cardiopulmonary resuscitation following cardiac arrest. Implication of the protein C anticoagulant pathway. J Am Coll Cardiol. 2005;46:21-8.

5. Kim J, Kim K, Lee JH, Jo YH, Kim T, Rhee JE, et al. Prognostic implication of initial coagulopathy in out-of-hospital cardiac arrest. Resuscitation. 2013;84:48-53.

6. Wada T, Gando S, Mizugaki A, Yanagida Y, Jesmin S, Yokota H, et al. Coagulofibrinolytic changes in patients with disseminated intravascular coagulation associated with post-cardiac arrest syndrome - Fibrinolytic shutdown and insufficient activation of fibrinolysis lead to organ dysfunction. Thromb Res. 2013;132:e64-9.

7. Levi M, ten Cate H. Disseminated intravascular coagulation. N Engl J Med. 1999;341:586-92

8. Mehta B, Briggs DK, Sommers SC, Karpatkin M. Disseminated intravascular coagulation following cardiac arrest: a study of 15 patients. Am J Med Sci. 1972;264:353-63.

9. Hayakawa H, Sawamura A, Yanagida Y, Sugano M, Kubota M, Hoshino H, et al. Insufficient production of urinary trypsin inhibitor for neutrophil elastase release after cardiac arrest. Shock. 2008:29:549-52.

10. Shyu KG, Chang H, Lin CC, Huang FY, Hung CR. Concentrations of serum interleukin-8 after successful cardiopulmonary resuscitation in patients with cardiopulmonary arrest. Am Heart J. 1997;134:551-6.

11. Gando S, Nanzaki S, Morimoto M, Kobayashi S, Kemmotsu O. Tissue factor and tissue factor pathway inhibitor levels during and after cardiopulmonary resuscitation. Thromb Res. 1999;96:107-13.

12. Gando S, Kameue T, Nanzaki S, Nakanishi Y. Massive fibrin formation with consecutive impairment of fibrinolysis in patients with out-of-cardiac arrest. Thromb Haemost. 1997;77:278-82.

13. Geppert A, Zorn G, Delle-Karth G, Heinz G, Murer G, Siostrzonik P, et al. Plasminogen activator inhibitor type 1 and outcome after successful cardiopulmonary resuscitation. Crit Care Med. 2001:29:1670-7.

14. Asakura $\mathrm{H}$. Classifying types of disseminated intravascular coagulation: clinical and animal models. J Intensive Care. 2014:2:20.

15. Ono Y, Hayakawa M, Wada T, Sawamura A, Gando S. Effects of prehospital epinephrine administration on neurological outcomes in patients with outof-hospital cardiac arrest. J Intensive Care. 2015;3:29.

16. Ferreira FL, Bota DP, Bross A, Mélot C, Vincent JL. Serial evaluation of the SOFA score to predict outcome in critically ill patients. JAMA. 2001;286:1754-8.

17. Members of the American College of Chest Physicians/Society of Critical Care Medicine Consensus Conference committee. American College of Chest Physicians/Society of Critical Care Medicine Consensus Conference. Definition for sepsis and organ failure and guidelines for the use innovative therapies in sepsis. Crit Care Med. 1992;20:864-74.

18. Gando S, Saitoh D, Ogura H, Mayumi T, Koseki K, Ikeda T, et al. Japanese Association for Acute Medicine disseminated intravascular coagulation (JAAM DIC) study group. Natural history of disseminated intravascular coagulation diagnosed based on the newly established diagnostic criteria for critically ill patients: Results of a multicenter, prospective survey. Crit Care Med. 2008;36:145-50.

19. Dellinger RP, Levy MM, Rhodes A, Annane D, Gerlach H, Opal SM, et al. Surviving sepsis campaign: international guidelines for management of severe sepsis and septic shock: 2012. Crit Care Med. 2013;41:580-637.

20. Szymanski FM, Karpinski G, Filipiak KJ, Platek AE, Hrynkiewicz-Szymanska A, Kotkowski $M$, et al. Usefulness of the D-dimer concentration as a predictor of mortality in patients with out-of-hospital cardiac arrest. Am J Cardiol. 2013;112:467-71.

21. Viersen VA, Greuters S, Korfage AR, Van der Rijst C, Van Bochove V, Nanayakkara PW, et al. Hyperfibrinolysis in out of cardiac arrest is associated with markers of hypoperfusion. Resuscitation. 2012;83:1451-5.

22. Duvekot A, Viersen VA, Dekkar SE, Geeraedts LMG, Schwarte LA, Spoelstra-Man AME, et al. Low cerebral oxygenation levels during resuscitation in out-of-hospital cardiac arrest are associated with hyperfibrinolysis. Anesthesiology. 2015;123:820-9.

23. Schwameis M, Schober A, Schörgenhofer C, Sperr WR, Schöchl H, JanataSchwatczek K, et al. Asphyxia by drowning induces massive bleeding due to hyperfibrinolytic disseminated intravascular coagulation. Crit Care Med. 2015:43:2394-402.

24. Clearke RL, Clifton EE. Oxygen saturation and spontaneous fibrinolytic activity. Am J Med Sci. 1962;244:466-71.

25. Todd AS. Endothelium and fibrinolysis. Atherosclerosis. 1972;15:137-40.

26. Bätsch P, Haeberli A, Hauser K, Gubser A, Straub PW. Fibrinogenolysis in the absence of fibrin formation in severe hypobaric hypoxia. Aviat Space Environ Med. 1988:59:428-32.

27. Schneiderman J, Adar R, Savion N. Changes in plasmatic tissue-type plasminogen activator and plasminogen activator inhibitor activity during acute arterial occlusion associated with ischemia. Thromb Res. 1991:62:401-8.

28. Schneiderman J, Eguchi Y, Adar R, Sawdey M. Modulation of fibrinolytic system by major peripheral ischemia. J Vasc Surg. 1994;19:516-24.

29. Lowenstein CJ, Morrell CN, Yamakuchi M. Regulation of Weibel-Palde body exocytosis. Trend Cardiovasc Med. 2005:15:302-8.

30. Pinsky DJ, Liao H, Lawson CA, Yan SF, Chen J, Cameliet P, et al. Coordinated induction of plasminogen activator inhibitor-1 (PAl-1) and inhibition of plasminogen activator gene expression by hypoxia promotes pulmonary vascular fibrin deposition. J Clin Invest. 1998;102:919-28.

\section{Submit your next manuscript to BioMed Central and we will help you at every step:}

- We accept pre-submission inquiries

- Our selector tool helps you to find the most relevant journal

- We provide round the clock customer support

- Convenient online submission

- Thorough peer review

- Inclusion in PubMed and all major indexing services

- Maximum visibility for your research

Submit your manuscript at www.biomedcentral.com/submit
) Biomed Central 